\title{
A Population-based Study on Pediatric Spinal Cord Tumors, with Emphasis on Intramedullary Ones
}

Maysa Al-Hussaini ${ }^{1 *}$ and lyad Sultan ${ }^{2}$

${ }^{1}$ Department of Pathology, King Hussein Cancer Center (KHCC), Amman, Jordan

${ }^{2}$ Department of Pediatric Oncology, King Hussein Cancer Center (KHCC), Amman, Jordan

\begin{abstract}
Purpose: Pediatric spinal cord tumors are rare accounting for $4-6 \%$ of all primary CNS tumors in this age group. Collecting large number of cases has always been difficult due to their scarcity. SEER database provides a source on various tumors.
\end{abstract}

Methods: We performed analysis on tumors of the spinal cord in patients between births to 20 years of age using the SEER data available for the period 1973-2005. Analysis of the incidence rate, the frequency of the most common types, the age, gender, treatment modality including radiotherapy and surgery is provided. In addition; the overall survival and the median survival has been analyzed for each tumor type and comparison between various types is performed.

Results: There were 483 cases of spinal cord tumors with available data, representing $4.7 \%$ of all pediatric central nervous system tumors diagnosed over the same period. They predominated in males and in whites. The median age for diagnosis was 10 years, with two age peaks noted; in $<3$ years old and in adolescents 12 to 17 years old. Of intramedullary tumors astrocytoma was the most common histology followed by ependymoma. Low grade tumors predominated. Of all variables examined; histologic type, grade, gross total resection and not receiving radiotherapy showed significant association with outcome.

Conclusions: Low- grade astrocytoma is the most common intramedullary tumor in first 2 decades of life, while ependymoma is mostly seen in the second decade of life. Assigning the appropriate histologic type and grade is important in determining the outcome of the patients.

Keywords: Spinal tumors; Intramedullary; Pediatrics; SEER; Astrocytoma; Ependymoma

\section{Introduction}

Spinal cord tumors are rare, representing 3-6\% of all central nervous system (CNS) tumors in pediatric age groups $[1,2]$. These tumors are divided according to their relation to the anatomy of the spinal cord into extradural, intradural-extramedullary and intramedullary tumors. Intramedullary spinal cord tumors (IMSCTs) account for 25$35 \%$ of all pediatric spinal tumors $[3,4]$ and $1-2 \%$ of all pediatric CNS tumors. In contrast to adults, the most common pediatric IMSCTs are astrocytomas, predominantly low grade astrocytoma $[5,6]$. Ependymomas are rarely encountered in the pediatric population below the age of 5 years [5] but the incidence increases gradually with age [7], where ependymomas represent the most common spinal tumors in adults [8]. Because of their rarity, studying IMSCTs has always been limited to series with small number of cases $[9,10]$, or focusing on the treatment related issues [11], or lumping adults and children together [12] with only few reporting on larger number of pediatric patients [13]. The Surveillance, Epidemiology and End-Results (SEER) database provides an opportunity of studying rare tumors. In this report we are trying to shed light on the incidence rate as well as the most important prognostic factors of the two most common IMSCTs in pediatrics, namely astrocytomas and ependymomas.

\section{Patients and Methods}

The data of studied patients was obtained from the Surveillance, Epidemiology, and End Results (SEER) 17 registries [1,14]. We used Case listing session of the SEER ${ }^{\star}$ Stat 6.4.4 program to generate a matrix of all children ( $<20$ years old) diagnosed with spinal tumors from 1973 to 2005. A selection query was designed to retrieve tumors based on the primary site location of 72.0 (spinal cord), 70.1 (spinal meninges) or 72.1 (Cauda Equina). Patients without histologic confirmation were excluded. Data was then analyzed using MedCalc for Windows, version 9.6.4.0 (MedCalc Software, Mariakerke, Belgium). Tumor grades were assigned based on 2007 WHO classification for primary tumors of the central nervous system [15] using histologic subtype for assignment, e.g. glioblastoma was assigned to grade IV. Only for tumors that the investigators were not sure of true grade based on provided information, we used SEER grades provided in the database, when available. Also, tumors were assigned to intramedullary, extramedullary and extradural according to the usual location of the tumor based on histologic subtype. Survival was calculated using Kaplan-Meier method considering all-cause mortality as an endpoint. Log-rank test was used to compare survival curves.

\section{Results}

We identified 507 children with spinal tumors in the SEER17 database. Twenty four patients were excluded due to lack of histological confirmation, leaving 483 patients for further analysis, including 92 cases of extradural, 20 cases of intradural extramedullary and 362 cases of intramedullary tumors and 9 cases in which the exact location could not be assigned. Patients were diagnosed from January 1973 through December 2005 and represented $4.7 \%$ of all pediatric patients with central nervous system tumors diagnosed in the same period.

*Corresponding author: Maysa Al-Hussaini, MD FRCPath, Department of Pathology, King Hussein Cancer Center, 202 Queen Rania Street, P.O. Box 1269 Al-Jubeiha, Amman 11941, Jordan, Tel: 962-6-5300-460-1308; Fax: 962-6-5300460-1552; E-mail: mhussaini@khcc.jo

Received May 13, 2013; Accepted June 17, 2013; Published June 19, 2013

Citation: Al-Hussaini M, Sultan I (2013) A Population-based Study on Pediatric Spinal Cord Tumors, with Emphasis on Intramedullary Ones. J Spine 2: 137 doi:10.4172/2165-7939.1000137

Copyright: ( 2013 Al-Hussaini M, et al. This is an open-access article distributed under the terms of the Creative Commons Attribution License, which permits unrestricted use, distribution, and reproduction in any medium, provided the original author and source are credited. 
Characteristics of studied patients are provided in Table 1 . There were more males $(58 \%)$ and white patients $(81 \%)$ in the studied population. The median age of studied patients was 10 years (range, birth to less than 20 years of age). Age distribution of patients showed 2 peaks, an earlier peak in young patients $(<3$ years old) and another peak in adolescents (12 to 17 years old, Figure 1A). Limited data were available regarding local control of these tumors in the form of extent of surgery and radiotherapy. No data was available regarding systemic therapy.

The median age for patients with extradural and extramedullary tumors was 7 years and 14.5 years, respectively. The most common extradural tumor was neuroblastoma (32 out of 92 tumors, 35\%) while the most common extramedullary tumor was neurolimmoma (11 out of $20 ; 55 \%)$.

Intramedullary tumors constituted $75 \%$ of cases of spinal cord tumors and the most common histologic subtypes were gliomas (51\%), mostly astrocytic tumors, and ependymoma (18\%).

Astrocytic tumors were the most common intramedullary tumor seen in all age groups (Figure 1B), the median age of patients with astrocytoma was 9 years, which is younger than the median age for the whole group, and frequency was similar in different age groups. They were seen slightly more in males (58\%). The majority of astrocytomas were low grade tumors (grade I pilocytic astrocytomas, $40 \%$; grade II astrocytoma, 32\%) while less than one third of these tumors were high grade (grade III anaplastic astrocytoma, 18\%; grade IV glioblastoma, $10 \%)$. Among patients with gliomas, $37 \%$ received radiotherapy and $33 \%$ of patients with reported surgical-procedure type $(n=160)$ had gross total resection (GTR).

On the other hand, there were 85 cases of ependymoma which were seen mainly in older patients, with a median age of 14 years, which is older than the median age for the whole group (Figure 1B). Similar to other spinal tumors, there was a slight male predominance (58\%). The majority of ependymomas were histologically labeled as "not otherwise specified" (NOS, 71.6\%), which would correspond to WHO grade II. There were 22 cases (26\%) labeled as myxopapillary ependymoma (WHO grade I) and only 2 cases (2.4\%) of anaplastic ependymoma (WHO grade III). Radiotherapy was used in $31 \%$ of patients with ependymoma while GTR was reported in $49 \%$ of 47 patients with available surgical data. Details of treatment and other features of spinal tumors are provided in Table 2.

Most deaths occurred in the first 5 -years (88\% of all reported deaths) which made this point suitable to compare survival estimates in patients with different clinical factors. The 5-year survival of all studied patients was $70 \% \pm 2.4 \%$. As a group, intramedullary tumors had the best survival when compared to other groups $(\mathrm{p}=0.0085)$. The 5 -year survival estimates for patients with glioma and ependymoma were $72 \% \pm 3.1 \%$ and $86 \% \pm 4 \%$, respectively. The majority of deaths $(n=112)$ were attributable to cancer $(n=102,91 \%)$. Histologic type and tumor grade, when available, were both significant prognostic factors in predicting survival (log-rank test; $p$ values of 0.0048 and $<0.0001$, respectively; Figure 1C and 1D). Patients who underwent GTR had better 5 -year survival $(84 \% \pm 4.5 \%$ vs. $66 \% \pm 2.8 \%$ in patients who were not reported to have GTR, $\mathrm{p}=0.0003$ ). Conversely, patients who did not receive radiation had better survival $(83 \% \pm 2.6 \%$ vs. $51 \% \pm$ $4.1 \%$ for those who received radiotherapy, $\mathrm{p}<0.001)$; the latter finding might be caused by radiotherapy delivered to more aggressive tumors. On the other hand, sex $(\mathrm{p}=0.78)$ and race $(\mathrm{p}=0.85)$ were not significant predictors of survival. Young patients with ependymoma $(<10$ years old, $n=20)$ had a trend toward better survival than older patients $(n=65$, $\mathrm{p}=0.076$ ).
We then looked specifically at children $<3$ years old at diagnosis. Among these patients, intramedullary tumor constituted almost twothirds of spinal tumors (66 out of 105); the majority of these tumors were gliomas $(n=51)$, with only 3 ependymoma cases. Patients less than 3 years were less likely to receive radiotherapy than older children ( $19 \%$ and $41 \%$, respectively; $\mathrm{p}<0.001)$ and to undergo GTR $(21 \%$ and $29 \%$, respectively; $\mathrm{p}=0.13$ ), although the latter did not reach statistical significance. The 5-year survival of patients less than 3-years with spinal tumors was $77 \% \pm 4.5 \%$ and for those with intramedullary tumors was $82 \% \pm 5.4 \%$ which were not statistically different from older children ( $\mathrm{p}=0.23$ and $\mathrm{p}=0.17$, respectively).

\section{Discussion}

This is one of the largest series on spinal cord tumors in children. The findings come at large in concordance with previously published data. Pediatric spinal cord tumors are rare, with an age-adjusted incidence rate of 0.26 per 100,000 [16], representing $4.7 \%$ of all pediatric CNS tumors described in the SEER database. In this group, intra-medullary spinal cord tumors (IMSCTs) accounted for three fourths of all reported cases, thus represented the most common type of spinal cord tumors in this age group. This finding is supported by some $[1,10,11,16]$, but not by all published literature on spinal cord tumors [17]. The difference distribution of spinal tumors in this study can be explained by the fact that SEER database records only primary tumor, excluding metastatic lesions - commonly extramedullary.

\begin{tabular}{|c|c|c|}
\hline Variable & $N(483)$ & $(\%)$ \\
\hline \multicolumn{3}{|l|}{ Age (years) } \\
\hline Median & 10 & \\
\hline \multicolumn{3}{|l|}{ Sex } \\
\hline Female & 203 & $(42)$ \\
\hline Male & 280 & $(58)$ \\
\hline \multicolumn{3}{|l|}{ Race } \\
\hline White & 392 & (81) \\
\hline Black & 54 & (11) \\
\hline Others & 37 & $(7.7)$ \\
\hline \multicolumn{3}{|l|}{ Types } \\
\hline \multicolumn{3}{|l|}{ Intramedullary } \\
\hline Glioma & 244 & (51) \\
\hline Ependymoma & 85 & $(18)$ \\
\hline Others intramedullary ${ }^{a}$ & 33 & $(6.8)$ \\
\hline Extramedullary & 20 & (4.1) \\
\hline Extradural & 92 & (19) \\
\hline Others/NOS ${ }^{b}$ & 9 & (1.9) \\
\hline \multicolumn{3}{|l|}{ Grade } \\
\hline 1 & 102 & (21) \\
\hline II & 123 & $(25)$ \\
\hline III & 43 & (8.9) \\
\hline IV & 55 & (11) \\
\hline Others/unknown & 160 & (33) \\
\hline \multicolumn{3}{|l|}{ Radiation } \\
\hline Received & 177 & (37) \\
\hline None/Refused/unknown & 306 & (63) \\
\hline \multicolumn{3}{|l|}{ Status } \\
\hline Alive & 354 & (73) \\
\hline Dead & 129 & $(27)$ \\
\hline
\end{tabular}

a, germ cell tumors $(n=3)$, astroblastoma $(n=1)$, primitive neuroectodermal tumor $(n=20)$, anaplastic ganglioglioma $(n=3)$, AT/RT $(n=2)$, hemangioblastoma $(n=2)$, gangliocytoma $(n=2)$; b, malignant neoplasm $(n=7)$, small cell tumor $(n=1)$ and malignant peripheral nerve sheath tumor $(n=1)$

Table 1: Patient characteristics. 


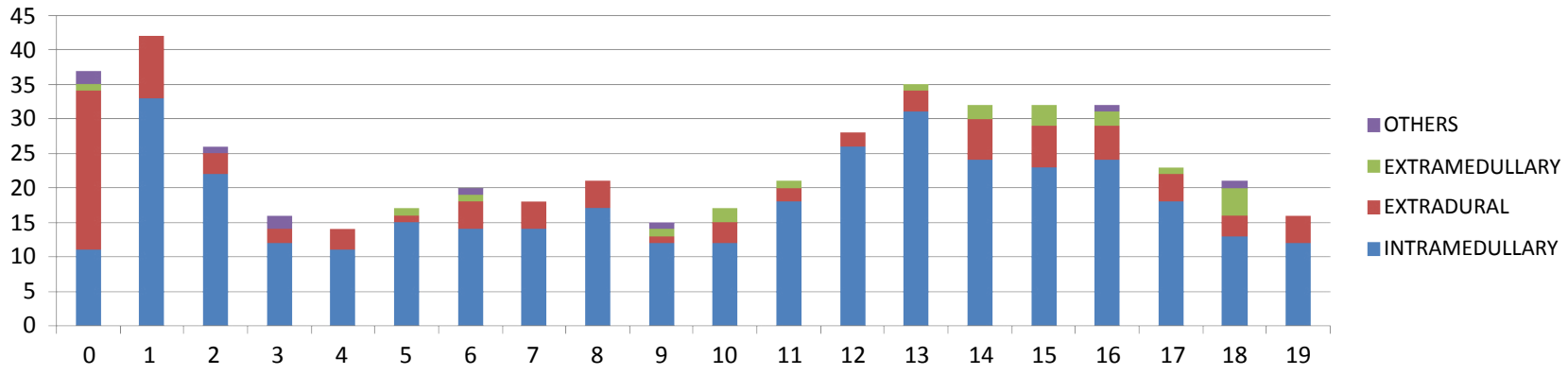

Figure-1 A: Incidence of different groups of spinal cord tumors in children.

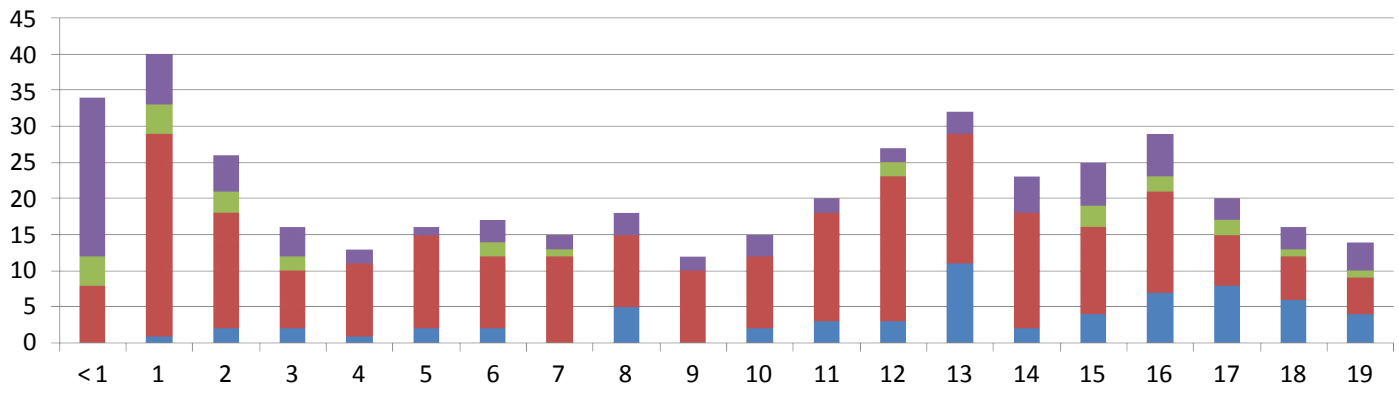

OTHERS (NON-CNS) OTHERS (CNS) -ASTOCYTOMA -EPENDYMOMA

Figure-1 B: Incidence by histological types of IMSCTs in children.

\begin{tabular}{|c|c|c|c|c|c|c|c|c|c|c|c|c|}
\hline & \multicolumn{4}{|c|}{ Grade } & \multirow{2}{*}{$\begin{array}{c}\text { Sex } \\
F(\%)\end{array}$} & \multicolumn{5}{|c|}{ Age } & \multicolumn{2}{|c|}{ Treatment } \\
\hline & 1 & II & III & IV & & $<1$ & 1 to 4 & 5 to 9 & 10 to 14 & 15 to 19 & XRT & GTR \\
\hline \multicolumn{13}{|l|}{ Intramedullary } \\
\hline Astrocytoma & 32 & 60 & 20 & 38 & $43 \%$ & 8 & 61 & 53 & 79 & 43 & 92 & 53 \\
\hline Ependymoma & 8 & 9 & 0 & 4 & $42 \%$ & 0 & 6 & 14 & 28 & 37 & 25 & 34 \\
\hline Extradural & 0 & 0 & 9 & 11 & $46 \%$ & 23 & 17 & 14 & 16 & 22 & 39 & 23 \\
\hline Extramedullary & 0 & 0 & 0 & 0 & $30 \%$ & 1 & 0 & 3 & 6 & 10 & 1 & 11 \\
\hline Others & 0 & 1 & 3 & 5 & $36 \%$ & 3 & 11 & 5 & 4 & 10 & 13 & 10 \\
\hline
\end{tabular}

GTR, gross total resection; XRT, radiation therapy given; numbers in table do not include unknown values, e.g. tumors with no grade specified

Table 2: Features and treatment of spinal tumors.

Benign tumors are not typically recorded by the SEER registries which also decrease the number of extramedullary and extradural tumors. Also, this analysis did not include tumors arising from the vertebral column, which are included in other reports.

These tumors were seen more commonly in boys and in whites as previously reported $[1,8,10,16]$.

Astrocytomas and ependymomas are the most common histologies of IMSCTs in childhood [18]. According to the WHO classification of tumors of CNS, there are 4 grades of astrocytic tumors; ranging from grade I pilocytic astrocytomas, grade II fibrillary astrocytomas, grade III anaplastic astrocytomas, to grade IV glioblastoma multiforme. Most IMSCTs gliomas were low grade (grade I and II). Only $28 \%$ of the gliomas in our study were high grade, which is slightly higher than previously reported [19]. Pilocytic astrocytoma appeared to be the single most common glioma affecting the spinal cord $[1,20]$, representing $75 \%$ of all astrocytomas and typically affects children in younger than 5 years of age. In contrast fibrillary astrocytomas tend to occur in older children [4]. This contrast with what was reported by Miller, where fibrillary astrocytoma was the predominant low grade tumor in his series from pediatric population, with only 4 pilocytic astrocytoma cases [12].

Ependymomas are rarely seen in patients younger than 3 years of age [5], which is usually encountered in the context of NF-2 in which mutations of NF2 gene on Chromosome 22 is a frequent finding $[21,22]$. Low grade ependymoma (grade I myxopapillary and grade II classic ependymoma) predominated in this series, representing $22.0 \%$ and $76.1 \%$ of ependymoma cases; respectively. High grade anaplastic ependymoma (WHO grade III) was rarely reported.

A variety of factors including histologic type [23], grade of the tumor $[13,24,25]$, radiotherapy [17], extent of surgery [17,26], extent of tumor outside the spine [24] are reported to affect the survival significantly. Grade of the tumor has been repetitively shown to be significant $[13,25,27]$, especially when low grade (I and II) are compared to high grade ones (III and IV) [19]. This is important to remember; especially when reporting neuro-pathologists are faced with small biopsies on which attempts to grade tumors becomes cumbersome. Age was found to affect survival and Boufett et al. [13] found that children younger than 7 years old with spinal tumors had better survival $(p=0.04)$. We 


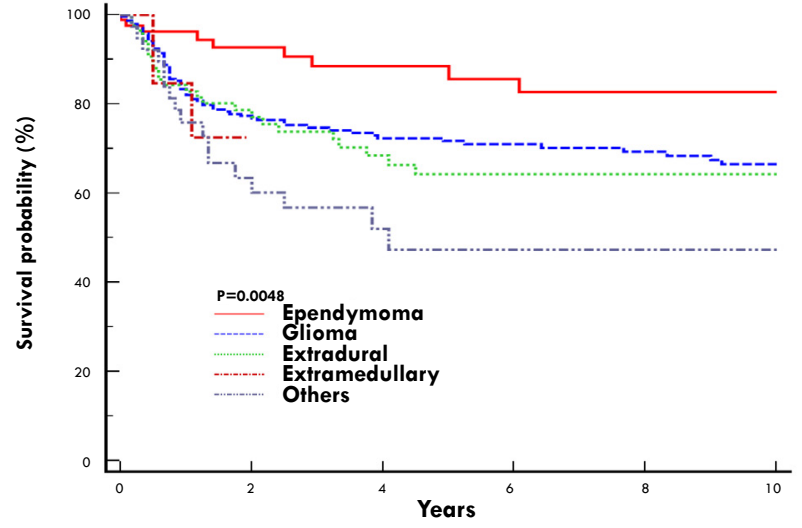

Figure- 1 C: Overall survival of children with IMSCTs by histological type.

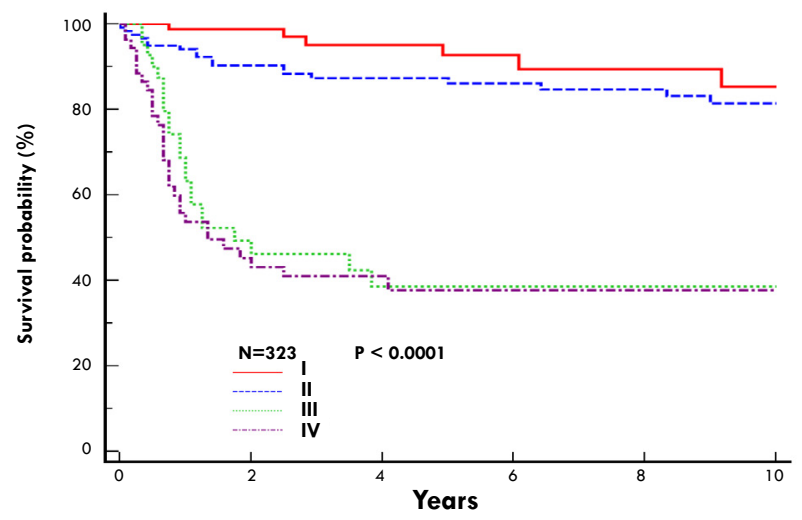

Figure- 1 D: Overall survival of children with IMSCTs by grade.

did not find the same results with this group of patients as most of cancer related deaths occurred in the first 5 years, and only younger patients with ependymoma ( $<10$ year) had a trend for better survival $(\mathrm{p}=0.076)$. The interaction of age with prognosis may reflect an inherited biological difference.

Of notice is the rarity of glio-neuroral tumors reported in this series with only 5 cases identified. Glio-neuronal tumors are reported as one of the common IMSCTs seen in children representing $35-41 \%$ of IMSCTs in this age group in some series $[5,12]$. These are biphasic tumors, with a mixture of glial and neuronal elements, usually in the form of dysplastic abnormal looking neurons. They are known for posing diagnostic difficulty and a potential for both over- or under- diagnostic pitfall, when normal looking entrapped neurons are considered part of the tumor, or when the neoplastic neurons are interpreted as being the pre-existing normal neurons, respectively [15]. They are more consistently diagnosed in resection versus biopsy specimens [12]. The under representation of glio-neuronal tumors in this series may reflect under-recognition of these tumors by reporting primary pathologists, or is merely a reflection of the neurosurgery practice in different institutions.

In management of IMSCTs, the extent of tumor resection remains a key issue [3]. Gross total resection was more commonly achieved in patients with ependymomas than in astrocytomas due to infiltrative nature of the later [7,17]. Radiotherapy should be preserved for cases in which less than total resection is achieved [23], or in case of high grade astrocytomas [28]. In children, the use of radiotherapy should only be offered after exhausting all other modalities due to the long term toxicity $[5,29]$. GTR and not receiving radiotherapy influenced the outcome in this series of patients. Patients who did not receive radiotherapy $(\mathrm{p}=0.001)$ and those who underwent GTR $(\mathrm{p}=0.0003)$ had a better survival.

There are inherent limitations to registry summary studies, because they do not take into account issues of histological verification, changing diagnostic and treatment approaches over time, limitations in non-reviewed imaging reporting, and other factors. The surprisingly rare glio-neuronal tumors may be due to the fact that such tumors may not have been widely diagnosed during a large part of the time period incorporated in the registry. Despite of that; SEER database offers the chance for studying rare tumors in a "cross-sectional" pattern which in the presence of large number of cases might represent a real reflection of the proportion of different diagnoses.

In conclusion, this is one of the largest series of spinal cord tumors in the children. It shows the predominance of low grade astrocytoma in IMSCTs. Ependymoma, which is the most common IMSCTs in adults, comes in second place in this series. Histology and grade are important determinant of the outcome, emphasizing the core role proper diagnosis be neuro-pathologist. GTR remains corner stone in the management of these tumors and radiotherapy should be offered only when GTR can't be achieved or in case of high grade tumors.

\section{References}

1. Auguste KI, Gupta N (2006) Pediatric intramedullary spinal cord tumors. Neurosurg Clin N Am 17: 51-61.

2. Stewart AM, Lennox EL, Sanders BM (1973) Group characteristics of children with cerebral and spinal cord tumours. Br J Cancer 28: 568-574.

3. Houten JK, Weiner HL (2000) Pediatric intramedullary spinal cord tumors: special considerations. J Neurooncol 47: 225-230.

4. Rossi A, Gandolfo C, Morana G, Tortori-Donati P (2007) Tumors of the spine in children. Neuroimaging Clin N Am 17: 17-35.

5. Constantini S, Houten J, Miller DC, Freed D, Ozek MM, et al. (1996 Intramedullary spinal cord tumors in children under the age of 3 years. J Neurosurg 85: 1036-1043.

6. Allen JC, Aviner S, Yates AJ, Boyett JM, Cherlow JM, et al. (1998) Treatment of high-grade spinal cord astrocytoma of childhood with "8-in-1" chemotherapy and radiotherapy: a pilot study of CCG-945. Children's Cancer Group. J Neurosurg 88: 215-220.

7. Houten JK, Cooper PR (2000) Spinal cord astrocytomas: presentation, management and outcome. J Neurooncol 47: 219-224.

8. Preston-Martin S (1990) Descriptive epidemiology of primary tumors of the spinal cord and spinal meninges in Los Angeles County, 1972-1985. Neuroepidemiology 9: 106-111.

9. Townsend N, Handler M, Fleitz J, Foreman N (2004) Intramedullary spinal cord astrocytomas in children. Pediatr Blood Cancer 43: 629-632.

10. Wilson PE, Oleszek JL, Clayton GH (2007) Pediatric spinal cord tumors and masses. J Spinal Cord Med 30 Suppl 1: S15-20.

11. McGirt MJ, Chaichana KL, Atiba A, Attenello F, Yao KC, et al. (2008) Resection of intramedullary spinal cord tumors in children: assessment of long-term motor and sensory deficits. J Neurosurg Pediatr 1: 63-67.

12. Miller DC (2000) Surgical pathology of intramedullary spinal cord neoplasms. J Neurooncol 47: 189-194.

13. Bouffet E, Pierre-Kahn A, Marchal JC, Jouvet A, Kalifa C, et al. (1998) Prognostic factors in pediatric spinal cord astrocytoma. Cancer 83: 2391-2399.

14. The Surveillance E, and End Results (SEER), National Cancer Institute USA.

15. Louis DN, Ohgaki H, Wiestler OD, Cavenee WK, Burger PC, et al. (2007) The 2007 WHO classification of tumours of the central nervous system. Acta Neuropathol 114: 97-109. 
16. Schellinger KA, Propp JM, Villano JL, McCarthy BJ (2008) Descriptive epidemiology of primary spinal cord tumors. J Neurooncol 87: 173-179.

17. Nadkarni TD, Rekate HL (1999) Pediatric intramedullary spinal cord tumors. Critical review of the literature. Childs Nerv Syst 15: 17-28.

18. Stiller CA, Nectoux J (1994) International incidence of childhood brain and spinal tumours. Int J Epidemiol 23: 458-464.

19. Santi M, Mena H, Wong K, Koeller K, Olsen C, et al. (2003) Spinal cord malignant astrocytomas. Clinicopathologic features in 36 cases. Cancer 98: 554-561.

20. Minehan KJ, Shaw EG, Scheithauer BW, Davis DL, Onofrio BM (1995) Spinal cord astrocytoma: pathological and treatment considerations. J Neurosurg 83: 590-595.

21. Ebert C, von Haken M, Meyer-Puttlitz B, Wiestler OD, Reifenberger G, et al. (1999) Molecular genetic analysis of ependymal tumors. NF2 mutations and chromosome $22 q$ loss occur preferentially in intramedullary spinal ependymomas. Am J Pathol 155: 627-632.

22. Egelhoff JC, Bates DJ, Ross JS, Rothner AD, Cohen BH (1992) Spinal MR findings in neurofibromatosis types 1 and 2. AJNR Am J Neuroradiol 13: 1071 1077.
23. Shirato H, Kamada T, Hida K, Koyanagi I, Iwasaki Y, et al. (1995) The role of radiotherapy in the management of spinal cord glioma. Int J Radiat Oncol Bio Phys 33: 323-328.

24. Schild SE, Nisi K, Scheithauer BW, Wong WW, Lyons MK, et al. (1998) The results of radiotherapy for ependymomas: the Mayo Clinic experience. Int $J$ Radiat Oncol Biol Phys 42: 953-958.

25. Jallo GI, Freed D, Epstein F (2003) Intramedullary spinal cord tumors in children. Childs Nerv Syst 19: 641-649.

26. Nishio S, Morioka T, Fujii K, Inamura T, Fukui M (2000) Spinal cord gliomas: management and outcome with reference to adjuvant therapy. J Clin Neurosci 7: $20-23$.

27. Merchant TE, Nguyen D, Thompson SJ, Reardon DA, Kun LE, et al. (1999) High-grade pediatric spinal cord tumors. Pediatr Neurosurg 30: 1-5.

28. Isaacson SR (2000) Radiation therapy and the management of intramedullary spinal cord tumors. J Neurooncol 47: 231-238.

29. Clayton PE, Shalet SM (1991) The evolution of spinal growth after irradiation Clin Oncol (R Coll Radiol) 3: 220-222. 